\title{
Parâmetros Curriculares Nacionais: Um Estudo sobre Orientação Sexual, Gênero e Escola no Brasil
}

\author{
Yáskara Arrial Palma ${ }^{1}$ \\ Faculdade de Desenvolvimento do Rio Grande do Sul - Laureate International Universities, \\ Porto Alegre, RS, Brasil \\ Aline da Silva Piason \\ Complexo de Ensino Superior de Cachoeirinha e Instituto Brasileiro de Gestão de Negócios, \\ Porto Alegre, RS, Brasil. \\ Almudena Garcia Manso \\ Universidad Rey Juan Carlos, Madrid, España \\ Marlene Neves Strey \\ Faculdade de Psicologia e Programa de Pós Graduação em Psicologia da Pontifícia \\ Universidade Católica do Rio Grande do Sul, Porto Alegre, RS, Brasil
}

\section{Resumo}

Este trabalho apresenta uma reflexão em relação às diretrizes e parâmetros curriculares que o governo brasileiro implementou, com o propósito de diminuir as diferenças sociais e culturais existentes no país. O objetivo desse estudo é investigar os Parâmetros Curriculares Nacionais (PCNs) buscando identificar e compreender de que modo a temática da orientação sexual é apresentada nos documentos oficiais. Para tanto, realizamos um estudo qualitativo com análise documental e posterior análise de discurso baseada nas teorias e estudos feministas de gênero. Os resultados apontam como positivo incluir a temática da orientação sexual nos currículos escolares a nível nacional, porém o modo como o termo é apresentado ainda é incipiente em relação à diversidade sexual, entendendo a mesma em um modelo higienista da sexualidade. É possível trabalhar a diversidade sexual com todas as suas facetas nas escolas; porém, a mesma precisa ser visibilizada, não somente nos documentos federais, como de modo geral na sociedade.

Palavras-chave: Educação, gênero, orientação sexual, parâmetros curriculares nacionais, diversidade sexual.

\section{Nationals Curriculars Parameters: A Study on Sexual Orientation, Gender and School in Brazil}

\begin{abstract}
This paper presents a reflection about guidelines and parameters for that the Brazilian government has implemented for schools, with the purpose of reducing the social and cultural differences existing in the country. The aim of this study is to investigate the Parametros Curriculares Nacionais (PCNs) in order to identify and understand how the issue of sexual orientation is presented in documents officials. This is a qualitative study with document analysis and subsequent discourse analysis based on feminist theories and gender studies. The results presented how positive include the issue of sexual orientation

Endereço para correspondência: Av. Rubem Bento Alves, 1469, 401 F, Caxias do Sul, RS, Brasil 95041-410. E-mail: yaskarapalma@yahoo.com.br, alinepiason@uol.com.br, almudena.manso@urjc.es e streymn@pucrs.br Apoio financeiro: Conselho Nacional de Desenvolvimento Científico e Tecnológico (CNPq) e Coordenação de Aperfeiçoamento de Pessoal de Nível Superior (CAPES).
\end{abstract}


in national school curricular, but the way the term is presented is still incipient about sexual diversity and understanding it in a model of sexuality hygienist. You can work sexual diversity in all its facets in schools; however, it needs to be visualized, not only in federal documents, as generally in society.

Keywords: Education, gender, sexual orientation, national curricular parameters, sexual diversity.

\section{Parámetros Curriculares Nacionales: Una Investigación de la Orientación Sexual, Género y la Escuela en Brasil}

\section{Resumen}

En este trabajo se presenta una reflexión en relación con las directrices curriculares y parámetros que el gobierno brasileño ha implementado, con el fin de reducir las diferencias sociales y culturales en el país. El objetivo de este estudio es investigar los Parâmetros Curriculares Nacionais (PCN) que tratan de identificar y comprender cómo se presenta el tema de la orientación sexual en los documentos oficiales. Por lo tanto, se realizó un estudio cualitativo con el análisis de documentos y el análisis del discurso posterior sobre la base de la teoría feminista y los estudios de género. Los resultados muestran como positivos poner el tema de la orientación sexual en los programas escolares en todo el país, pero la forma en que se presentó el plazo es aún incipiente en relación a la diversidad sexual, tiene una comprensión de la misma en un modelo de sexualidad y salud. Se puede trabajar la diversidad sexual en todas sus facetas en las escuelas, pero la misma tiene que ser mirada, no sólo en los documentos federales, como en general en la sociedad.

Palabras clave: Educación, género, orientación sexual, parámetros curriculares nacionales, diversidad sexual.

A escola é um lugar onde as diferenças convivem e interagem entre si, é esperado então, que apresente uma forma de agir no sentido de compreender a diversidade de pensamentos, crenças, etnias, religiões, sexualidades. Porém, mesmo em um espaço voltado para essa diversidade, encontramos na escola a manutenção de preconceitos e a formação de indivíduos/alunos(as) preconceituosos(as) (Baibich, 2002).

Quando pensamos em escola devemos pensar também em um espaço disciplinador e normatizador, e não somente em um espaço que auxilia a formar futuros cidadãos e cidadãs. Logo, ela não apenas transmite/constrói conhecimento, porém faz isso reproduzindo padrões sociais, perpetuando concepções, valores e clivagens sociais, fabricando sujeitos e legitimando relações de poder e hierarquias (Junqueira, 2009).

Sabemos que existe preconceito e discriminação na escola, e muitas vezes até manifestações de violência, em função de um não entendimento ao que é diferente. A sociedade possui padrões de comportamento socialmente esperados e de- sejados que aprisionam as pessoas em modos de comportamento, gerando, por exemplo, violências de lesbofobia, homofobia e transfobia.

Uma pesquisa realizada no Rio de Janeiro - Brasil que possuía o objetivo de discutir sobre a violência contra homossexuais no ambiente escola entrevistou vinte adolescentes do sexo masculino, que se auto-identificam como homossexuais, todos discentes da Universidade Federal Fluminense (UFF). Os dados revelaram através de narrativas relacionadas à violência sofrida na época escolar dos entrevistados que a escola pode ser entendida como um lugar de violência física e psicológica (Góis \& Soliva, 2011).

Para assegurar uma formação básica comum nas escolas de todo o país, o governo brasileiro criou políticas, como a implantação em 1998 dos Parâmetros Curriculares Nacionais (PCNs), a partir da Lei de Diretrizes e Bases da Educação Nacional (LDB) de 1996. Essa política estabeleceu a criação de currículos e conteúdos mínimos para a educação infantil, ensino fundamental e ensino médio (Daniliauskas, 2011). Esses parâ- 
metros também prevêem que as questões relacionadas à sexualidade passem a ser trabalhadas nas escolas, para auxiliar no combate à violência e à discriminação. Espera-se que a possibilidade da discussão da temática sexualidade possa ampliar o modo de entendimento de crianças e adolescentes e como consequência, diminuir os dados de violência dentro das escolas com relação à diversidade sexual.

\section{A "Orientação Sexual" Vista Através das Lentes dos PCNs: Implicações na Escola e na Família}

$\mathrm{O}$ fato do governo intensionar um debate sobre a sexualidade pode ser considerado como algo positivo, visto que em algumas décadas atrás, esse assunto não era nem permitido, quanto mais estimulado. Porém, é importante refletir sobre a maneira como a sexualidade está sendo abordada, senão podemos recair no histórico de tratarmos a sexualidade simplesmente associada à promoção da saúde sexual e à prevenção de gravidez e outras doenças sexualmente transmissíveis (Meyer, Klein, \& Andrade, 2007).

A maneira de trabalhar a orientação sexual, e com ela a diversidade, vai variar dependendo a fase de vida que a criança se encontra. Os PCNs também vão apresentar essa variação para o ensino infantil, fundamental e médio, propondo um modo de trabalho específico em cada PCN. Para o ensino infantil, não existe uma sessão específica sobre sexualidade.

No ensino fundamental, tanto para $1^{\mathrm{a}}$ a $4^{\mathrm{a}}$ séries, como para $5^{\mathrm{a}}$ a $8^{\mathrm{a}}$, a orientação sexual ocupa um parte das disciplinas relacionadas a "temas transversais" e no ensino médio não existe nada específico sobre orientação sexual, sendo que essa questão será abordada de maneira bastante sucinta em uma parte complementar aos PCNs.

Ter a possibilidade de trabalhar questões relacionadas à orientação sexual (esclarecendo que o termo orientação, neste caso dos PCNs, refere-se ao ato de propor um espaço de discussão sobre a sexualidade, e não está relacionado com o direcionamento da escolha de parceiros ou parceiras) nas escolas, e dentre ela a questão da diversidade, é um avanço no ensino brasilei- ro. A escola não pode simplesmente fechar os olhos para a realidade, e considerar que as palavras: gay e lésbica devem ficar fora dos portões escolares.

Levando em consideração a história da homossexualidade, podemos perceber que ao longo dos tempos, principalmente em função da luta dos movimentos sociais, o modo de perceber a orientação sexual que difere da heterossexual foi sendo modificada. O DSM IV (Manual de Psiquiatria), publicado em 1994, retirando o rótulo de doença e considerando a homossexualidade apenas como uma das maneiras de direcionar o desejo sexual contribui bastante para que passasse a haver uma visibilização da orientação gay e lésbica, não mais escondida, mas assumida e lutando por ter seus direitos (Uziel, 2007; Zambrano, 2006).

Esse fato modificou muito o cenário da sala de aula de algumas décadas atrás para os tempos atuais. Crianças advindas de lares constituídos por duas mães ou dois pais há muito tempo frequentam as salas de aula, porém estigmatizadas em função da invisibilidade. Com as recentes conquistas dos casais do mesmo sexo, mais especificamente em relação ao direito de realmente serem consideradas Famílias, essa invisibilidade pode ser transformada ("Veja as Declarações", 2011).

Porém, a visibilidade sem um trabalho de respeito à diversidade não modifica um cenário de preconceitos e discriminações. Essas crianças provavelmente sofrem na atualidade algo já passado pelas crianças advindas de lares com pai e mãe separados (Kyriakos, 2006), pois o que vai "contra" uma norma social provoca reações e tentativas de voltar a um suposto equilíbrio da sociedade.

Então temos uma realidade atual bastante diversa, principalmente no que se refere à orientação sexual. Além de existirem crianças em sala de aula com duas mães ou dois pais, há crianças que mesmo sendo meninas não se interessam por meninos e vice-versa, além de outras crianças que não se sentem confortáveis com o sexo que nasceram. E com todas essas possibilidades, é muito difícil que o tema da diversidade sexual 
não seja abordado, e que a realidade de inúmeras crianças tenha que ser "abafada".

Por passarem por essas situações negativas, adolescentes gays, lésbicas e transgêneros possuem maior probabilidade de cometerem suicídio, quando comparado com seus iguais heterossexuais. Também revelam que em geral, são obrigados(as) a abandonar os estudos devido aos preconceitos que sofrem por não seguirem os padrões heteronormativos (Mello, Grossi, \& Uziel, 2009).

A responsabilidade para tratar o tema da sexualidade, muitas vezes, é alternada da escola para a família e da família para a escola, sendo que ambos são responsáveis de tratar sobre essa questão. Porém mesmo a escola ampliando a discussão do assunto, é importante que a família em casa também continue o trabalho, para que não se torne algo proibido e também para que a família possa estar o mais consoante possível com o aprendizado de seus filhos e filhas (Almeida \& Centa, 2009).

Estudos norte-americanos da década de oitenta e noventa apontam que as crianças advindas de lares lésbicos e gays se comportam de modo mais tolerante e compreensivo, tornando-se adultos com menos preconceitos (Gold, Perrin, Futterman, \& Friedman, 1994, Golombok \& Tasker, 1996; Tasker, 2005). Mas de nada adianta essas crianças advindas de famílias diversificadas entenderem e respeitarem o que lhes é diferente, se a escola não lidar com a diversidade da mesma maneira como trata outros assuntos, ou não trabalhar os/as colegas para que possa existir uma atmosfera de respeito mútuo entre as crianças e adolescentes.

Fixar os estudos sobre a sexualidade em uma abordagem biológico-higienista, onde o foco será a promoção da saúde, a reprodução humana, doenças sexualmente transmissíveis (DSTs), gravidez indesejada, planejamento familiar, entre outros (Furlani, 2011) só reitera que a temática deve ser tratada com cuidados, por ser algo prejudicial, logo, temida. E retrocedemos ao século XVII, desvinculando afeto de prazer, separando prazer e sexualidade para assuntos de outra ordem, proibidos e ainda passíveis de repressão (Ariès, 1981).

\section{Método}

O estudo seguiu um delineamento qualitativo, de caráter descritivo e exploratório. Os documentos escolhidos para a análise neste estudo são os PCNs para o Ensino Infantil, Fundamental e Médio. A escolha por esses documentos ocorreu por julgarmos que eles poderão contribuir para que possamos chegar ao nosso objetivo, que é investigar as propostas e intenções que estão sendo criadas para contemplar a diversidade, mais especificamente a diversidade sexual.

Os PCNs são compostos de inúmeros subitens, dependendo a faixa de ensino que estão propostos. Os PCNs Ensino Infantil estão compostos pela Ficha Técnica, Volume 1, Volume 2 e Volume 3. Já os voltados para o Ensino Fundamental estão divididos em dois momentos, de $1^{\mathrm{a}}$ a $4^{\mathrm{a}}$ série, composto por: Introdução, Língua Portuguesa, Matemática, Ciências Naturais, História e Geografia 1 e 2, Arte, Educação Física, Temas Transversais (Apresentação e Ética), Meio Ambiente, Saúde, Pluralidade Cultural e Orientação Sexual.

O outro momento refere-se ao intervalo da $5^{\mathrm{a}}$ a $8^{\mathrm{a}}$ série, e possui: Introdução, Língua portuguesa, Matemática, Ciências Naturais, Geografia, História, Arte, Educação Física, Língua Estrangeira, Temas Transversais (Apresentação, Pluralidade Cultural, Meio Ambiente, Saúde e Orientação Sexual). O Ensino Médio está dividido em quatro itens: Bases Legais, Linguagens, códigos e suas tecnologias, Ciências da natureza, matemática e suas tecnologias e Ciências humanas e suas tecnologias. Os PCN + são orientações educacionais complementares do ensino médio, e correspondem aos três últimos itens dos quatro descritos acima.

Como o nosso interesse está voltado para o tema da orientação sexual, definimos alguns itens específicos para analisar, por considerarmos que nessas partes poderíamos encontrar notícias do assunto em questão. São eles: Ensino Infantil- Volume 1, 2 e 3, Ensino Fundamental (de $1^{\mathrm{a}}$ a $4^{\mathrm{a}}$ séries e de $5^{\mathrm{a}}$ a $8^{\mathrm{a}}$ séries)- Orientação sexual dos temas transversais, Ensino Médio Linguagens, códigos e suas tecnologias ( $\mathrm{PCN}$ e 
PCN +) e Ciências Humanas e suas tecnologias $(\mathrm{PCN}$ e $\mathrm{PCN}+)$.

Foi utilizada análise documental por entendermos que o exame de documentos permite uma ampla utilização de registros, interpretações e comentários, produzidos de diferentes formas e em diferentes épocas, sendo a revisão dos documentos pertinentes ao tema da pesquisa uma tarefa necessária em todas as etapas do estudo (Scarparo, 2000).

Os documentos utilizados no estudo em questão estão disponibilizados nas páginas da internet, no site do governo federal, tendo um acesso muito facilidade em função disso. Segundo Diniz, Barbosa, Junqueira e Prado (2009), a partir da década de noventa foi implementada no Brasil a prática de acessar o governo através do meio eletrônico, ficando essa prática conhecida como "e-gov". Essa iniciativa, que se iniciou na década de oitenta trouxe inúmeras contribuições para a sociedade, entre elas, o fácil e rápido acesso aos documentos federais.

Para a análise dos dados, utilizamos a análise de discurso proposta por Gill (2002), associada à ótica das teorias feministas dos estudos de gênero (Colling, 2004; Scott, 2002). Essas teorias feministas de gênero entendem o masculino como hegemônico nas diferentes sociedades, submetendo as mulheres a um papel de inferioridade, colocando-as à margem de um sistema patriarcal.

\section{Resultados e Discussão}

\section{Educação Infantil}

Foram eleitas para análise as partes do PCN Educação Infantil que fazem referência à sexualidade e à diversidade, encontradas nos volumes 1 e 2. O Vol. 1, no início do documento, comenta sobre a diversidade, mas não remetendo à sexualidade, mas sim à cultura e as diferenças entre as pessoas. O trecho a seguir nos exemplifica: "A prática da educação infantil deve se organizar de modo que as crianças desenvolvam as seguintes capacidades de conhecer algumas manifestações culturais, demonstrando atitudes de interesse, respeito e participação frente a elas e valorizan- do a diversidade" (Secretaria de Educação Fundamental, 1998, p. 10).

No trecho em questão, pensamos que a temática da sexualidade, principalmente no que se refere à orientação sexual poderia estar presente, pois a palavra diversidade refere-se a inúmeros modos de ser e viver. O Vol. 1 também faz referência à família, e nesse ponto notamos que a diversidade é trabalhada, mas sempre de maneira "velada", pois é feito referência sobre vários modos diferentes de se constituir uma família, porém em nenhum momento as palavras gays ou lésbicas são mencionadas:

Visões mais atualizadas sobre a instituição familiar propõem que se rejeite a ideia de que exista um único modelo. Enfoques teóricos mais recentes procuram entender a família como uma criação humana mutável, sujeita a determinações culturais e históricas que se constitui tanto em espaço de solidariedade, afeto e segurança como em campo de conflitos, lutas e disputa. (Secretaria de Educação Fundamental, 1998, p. 75)

Se o documento entende a família como mutável e sujeita a determinações culturais e históricas, deveria entender que a diversidade familiar está constituída por famílias de duas mães ou dois pais. Porém, fica somente subentendido, considerando talvez que Família seja a conhecida "nuclear burguesa". Esse discurso pode estar a serviço da manutenção do status quo da sociedade, baseado em um pensamento androcêntrico, considerando os homens como sujeitos de referência e as mulheres, seres dependentes que vivem em função deles, e o relacionamento entre um homem e uma mulher o único existente (Alario, Bengoechea, Lledó, \& Vargas, 1995).

E as famílias constituídas por duas mães, homomaternais (Palma, 2011) ou dois pais, homoparentais, passaram a ser assunto na década de oitenta e noventa. Após os movimentos sociais terem lutado pelo direito da igualdade e diversidade, e também após a homossexualidade deixar de ser entendida no meio "psi" como uma doença e passar a ser vista apenas como uma orientação sexual (Uziel, 2007; Zambrano, 2006). O parágrafo a seguir apresenta algumas dessas no- 
menclaturas, não mencionando às referentes ao tema homossexualidade e lesbianidade:

Além da família nuclear que é constituída pelo pai, mãe e filhos, proliferam hoje as famílias monoparentais, nas quais apenas a mãe ou o pai está presente. Existem, ainda, as famílias que se reconstituíram por meio de novos casamentos e possuem filhos advindos dessas relações. Há, também, as famílias extensas, comuns na história brasileira, nas quais convivem na mesma casa várias gerações e/ou pessoas ligadas por parentescos diversos. É possível ainda encontrar várias famílias coabitando em uma mesma casa. Enfim, parece não haver limites para os arranjos familiares na atualidade. (Secretaria de Educação Fundamental, 1998, p. 76)

No Vol. 2 também é expressa a importância da diversidade, porém o conceito é tratado no âmbito cultural, sem fazer menção ao âmbito da sexualidade: "Dependendo da maneira como é tratada a questão da diversidade, a instituição pode auxiliar as crianças a valorizarem suas características étnicas e culturais, ou pelo contrário, favorecer a discriminação quando é conivente com preconceitos" (Secretaria de Educação Fundamental, 1998, p. 14).

Esse "não falar sobre" pode estar associado à tradição judaico-cristã e sua relação com a temática homossexualidade, que contribuiu para que essa prática passasse a ser concebida pejorativamente. Somado a isso, a partir do século XIX, a medicina definiu a homossexualidade como uma doença fisiológica e, no início do século $\mathrm{XX}$, a psicanálise introduziu a visão psicológica da homossexualidade, considerando a mesma como um distúrbio no desenvolvimento da sexualidade e, portanto, anormal (Lacerda, Pereira, \& Camino, 2002).

Acaba sendo "politicamente correto" tratar de diversidade no século XXI, então se encontram preocupações com o respeito ao diferente, à inclusão escolar, à diminuição das desigualdades sociais (Furlani, 2011). Porém, essas preocupações podem estar pautadas em posicionamentos de "comoção/compreensão" e não na intencionalidade de propor uma transformação social.
Para que essa transformação possa ocorrer, é fundamental a criação de espaços de reflexão que permitam outras possibilidades de viver em sociedade.

Refletir sobre a temática- gênero- é fundamental, pois se for entendido que quem nasce mulher é, por conseqüência, feminina, está se fechando as possibilidades dessa mulher ser o que ela quiser. Está se esperando dela os atributos que a sociedade tem como "femininos", ou seja, essa mulher terá que ser meiga, gentil, delicada, compreensiva, entender de moda e gostar de usar maquiagem (Nicholson, 2000; Rago, 2004).

O texto continua e chega aos subtítulos: Respeito à diversidade e Identidades de Gênero. Porém, as palavras: gay e lésbica continuam não sendo mencionadas, e quando aborda diversidade, se fala em diversidade de gênero apenas, mas não menciona a questão do direcionamento do desejo sexual. Na parte: Identidades de Gênero há um desenvolvimento a respeito de que na contemporaneidade não deveria existir mais uma pré-definição de papéis, colocando homens e mulheres em sofrimento. O trecho abaixo nos apresenta essa questão:

No que concerne a identidade de gênero, a atitude básica é transmitir, por meio de ações e encaminhamentos, valores de igualdade e respeito entre as pessoas de sexos diferentes e permitir que a criança brinque com as possibilidades relacionadas tanto ao papel de homem como ao da mulher. Isso exige uma atenção constante por parte do professor, para que não sejam reproduzidos, nas relações com as crianças, padrões estereotipados quanto aos papéis do homem e da mulher, como, por exemplo, que à mulher cabe cuidar da casa e dos filhos e que ao homem cabe o sustento da família e a tomada de decisões, ou que homem não chora e que mulher não briga. (Secretaria de Educação Fundamental, 1998, p. 44)

\section{Ensino Fundamental $1^{a}$ a $4^{a}$ Séries}

Nos PCNs voltados para o Ensino Fundamental, mais especificamente para as quatro primeiras séries, optamos por analisar a parte referente especificamente à orientação sexual: 
Orientação sexual dos temas transversais. O texto inicia com uma apresentação da Secretaria de Educação Fundamental, explicando sobre a importância do trabalho com a sexualidade (lembrando novamente que o termo "orientação" estará sendo utilizado para se referir a direcionamentos e explicações sobre a sexualidade, não fazendo referência a outro modo de direcionar o desejo sexual, além do heterossexual).

Nesse texto de abertura, a frase que o finaliza explica que o objetivo do trabalho é promover reflexões sobre o assunto, levando em consideração: "os princípios morais de cada um dos envolvidos e respeitando, também, os Direitos $\mathrm{Hu}$ manos" (Secretaria de Educação Fundamental, 1998, p. 3). Podemos iniciar nossos questionamentos refletindo sobre o que seria a "moral de cada um", sendo que vivemos em uma sociedade ainda regida por padrões patriarcais e religiosos. Esse fato nos remete à necessidade de manter o status quo da sociedade, e com isso, perceber que a moral de cada um poderá ser a reiteração de introjeções advindas de um sistema heteronormativo.

O início do texto justifica o trabalho sobre a sexualidade, que data da década de oitenta, em função do crescimento de gravidez na adolescência e risco de contaminação pelo HIV. Essa justificativa nos remete ao controle social através da saúde-doença, isto é, promover prevenção para não precisar passar para o tratamento. Não traz uma preocupação com o desenvolvimento biopsicossocial de alunos e alunas, mas sim representa a necessidade da sociedade em manter o seu "controle".

Ao mesmo tempo, o texto reflete sobre as aulas de ciências, apontando que o aparelho reprodutor não é suficiente para englobar o "denso" território da sexualidade: "Essa abordagem normalmente não abarca as ansiedades e curiosidades das crianças, pois enfoca apenas o corpo biológico e não inclui as dimensões culturais, afetivas e sociais contidas nesse mesmo corpo" (Secretaria de Educação Fundamental, 1998, p. 5).

Mantém o foco na prevenção da saúde mais adiante:

O trabalho sistemático e sistematizado de

Orientação Sexual dentro da escola articula- -se, portanto, com a promoção da saúde das crianças e dos adolescentes. A existência desse trabalho possibilita também a realização de ações preventivas às doenças sexualmente transmissíveis/AIDS de forma mais eficaz. (Secretaria de Educação Fundamental, 1998, p. 7)

Percebemos uma ambiguidade no tratamento da questão sexualidade no discurso dos PCNs Ensino Fundamental $1^{\mathrm{a}}$ a $4^{\mathrm{a}}$ séries. Apesar de fazer uma tentativa de contribuir para um desenvolvimento global das alunas e dos alunos, falando em Direitos Humanos e a importância de conhecer a sua sexualidade, ainda se pauta na questão: controle social versus doença, focado em um momento histórico, onde o tema sexualidade estava voltado para o combate ao HIV (Lacerda et al., 2002), sem refletir sobre a importância do mesmo na contemporaneidade.

Podemos perceber que há avanços no modo de perceber o feminino e o masculino, porém o texto não trata abertamente dessas questões, vai sempre até um determinado ponto, dando a entender que pode estar falando de diversidade, como na parte que segue:

O trabalho de Orientação Sexual na escola é entendido como problematizar, levantar questionamentos e ampliar o leque de conhecimentos e de opções para que o aluno, ele próprio, escolha seu caminho ... . A escola deve informar e discutir os diferentes tabus, preconceitos, crenças e atitudes existentes na sociedade. (Secretaria de Educação Fundamental, 1998, p. 12)

Ainda nesse contexto, a mesma ideia segue expressa no trecho a seguir, onde as nomenclaturas "homossexualidade" ou outra ligada a esse contexto não são mencionadas:

No trabalho de Orientação Sexual são muitas as questões às quais se deve estar atento. Em primeiro lugar, trata-se de temática muito associada a preconceitos, tabus, crenças ou valores singulares. Para que o trabalho de Orientação Sexual possa se efetivar de forma coerente com a visão pluralista de sexualidade aqui proposta, é necessário que as diferentes crenças e valores, as dúvidas e os questionamentos sobre os diversos aspec- 
tos ligados à sexualidade encontrem espaço para se expressar. (Secretaria de Educação Fundamental, 1998, p. 16)

Finalizando o subcapítulo, aparecem mais conteúdos trabalhados a temática - gênero, e apesar de um discurso voltado para a diversidade, novamente o texto não vai abordar as diferentes formas de expressão do desejo sexual. Os conteúdos indicados para o trabalho são:

a diversidade de comportamento entre homens e mulheres, em função da época e do local em que vivem, a relatividade das concepções tradicionalmente associadas ao masculino e ao feminino, o respeito pelo outro sexo, na figura das pessoas com as quais se convive, o respeito às muitas e variadas expressões do feminino e do masculino. (Secretaria de Educação Fundamental, 1998, p. 29)

Falar em variadas expressões do feminino e do masculino é pensar em outros modos de expressão do desejo sexual que não o heteronormativo. E esse desejo pode estar presente nas alunas e nos alunos, como em suas mães e seus pais, e até mesmo em outras pessoas de seu convívio familiar e/social. Negar a existência de outras possibilidades de desejo reforça um comportamento pautado no patriarcado ainda presente em nossa sociedade, que historicamente, através de redes de poder e dominação, tentou apagar da história as relações entre pessoas do mesmo sexo (Piason \& Strey, 2011).

\section{Ensino Fundamental $5^{a}$ a $8^{a}$ Séries}

Os PCNs voltados para as últimas séries do ensino fundamental apresentam um conteúdo muito parecido com os voltados para as séries iniciais, porém agora identificamos avanços no sentido do tema da homossexualidade estar sendo mencionado. Na parte que fala sobre as temáticas a serem trabalhadas, estão citados os temas considerados "polêmicos", mas que serão abordados em função da curiosidade existe nas faixas etárias em questão.

A partir da quinta série do ensino fundamental, os questionamentos vão aumentando, exigindo progressivamente a discussão de temas polêmicos, como masturbação, início do relacionamento sexual, homossexualidade, aborto, prostituição, erotismo e pornografia, desempenho sexual, disfunções sexuais, parafilias, gravidez na adolescência, obstáculos na prevenção das doenças sexualmente transmissíveis/Aids, entre outros. (Secretaria de Educação Fundamental, 1998, p. 31)

E continua falando sobre a importância de também serem trabalhados temas que estão na mídia, como: "Questões como mães de aluguel, hermafroditismo, transexualismo, novas tecnologias reprodutivas, por exemplo, são trazidas por meio da veiculação pela mídia, aparecendo então como demanda efetiva de conhecimento e debate" (Secretaria de Educação Fundamental, 1998, p. 31).

Se por um lado a ideia de serem visibilizadas outras maneiras de expressão do desejo sexual poder representar avanços e vitórias em um terreno ainda "pantanoso", o modo como o assunto está sendo abordado recai novamente em mecanismos de regulação da sociedade. Esses mecanismos ainda mantêm a heterossexualidade como compulsória tratando, por exemplo, de "transexualismo" e "hermafroditismo" com sufixos que denotam doença, em documentos federais.

Retornando ao fator positivo dos PCNs ensino fundamental $5^{\mathrm{a}}$ a $8^{\mathrm{a}}$ séries trazerem as nomenclaturas referentes à homossexualidade, há uma grande preocupação em trabalhar com os/as alunos/as questões referentes ao não preconceito, o que pode ser exemplificado no trecho a seguir:

O trabalho com Orientação Sexual supõe refletir sobre e se contrapor aos estereótipos de gênero, raça, nacionalidade, cultura e classe social ligados à sexualidade. Implica, portanto, colocar-se contra as discriminações associadas a expressões da sexualidade, como a atração homo ou bissexual, e aos profissionais do sexo. (Secretaria de Educação Fundamental, 1998, p. 32)

Os PCNs construídos para trabalhar gênero de quinta a oitava série são realmente bastante consistentes e completos, incluindo inclusive possibilidades de trabalhar o tema em todas as 
disciplinas. A dificuldade novamente vai recair na temática relacionada a gays e lésbicas, pois o último parágrafo do subcapítulo Gênero vai trazer essas nomenclaturas, mas trabalhando a ideia dos estereótipos de gênero e não apresentando como outras maneiras de exercer a sexualidade:

Tome-se como exemplo a discussão do tema da homossexualidade. Muitas vezes se atribui conotação homossexual a um comportamento ou atitude que é expressão menos convencional de uma forma de ser homem ou mulher. Ela escapa aos estereótipos de gênero, tal como um menino mais delicado ou sensível ser chamado de "bicha" ou uma menina mais agressiva ser vista como lésbica, atitudes essas discriminatórias. Em cada período histórico e em cada cultura, algumas expressões do masculino e do feminino são dominantes e servem como referência ou modelo, mas há tantas maneiras de ser homem ou mulher quantas são as pessoas. Cada um tem o seu jeito próprio de viver e expressar sua sexualidade. Isso precisa ser entendido e respeitado pelos jovens. (Secretaria de Educação Fundamental, 1998, p. 41)

\section{Ensino Médio}

Dos PCNs direcionados para o Ensino Médio (PCNEM e PCNEM +), selecionamos para análise os referentes às Ciências Humanas e suas tecnologias e seu adicional $+(\mathrm{PCNEM}+)$ e também Linguagens, Códigos e suas tecnologias, e seu adicional + $(\mathrm{PCNEM}+)$ em função das temáticas que são tratadas nos documentos. Para o ensino médio, não existem diretrizes específicas para a orientação sexual, como no ensino fundamental, e nossa análise se fixou na busca desse assunto nos documentos direcionados para os/as jovens da faixa etária de 15 a 17 anos, aproximadamente.

Quando analisamos os parâmetros intitulados Ciências Humanas e suas tecnologias, não encontramos nada que fizesse referência à sexualidade, muito menos à diversidade sexual. No seu plus intitulado Ciências Humanas e suas tecnologias- orientações complementares aos parâmetros curriculares nacionais, encontramos um parágrafo falando sobre diversidade, mas nos mesmos moldes dos PCNs já analisados anteriormente, referentes ao ensino infantil e fundamental. Pode estar se referindo a uma ideia sobre diversidade sexual, mas pode também estar se referindo à cultura.

O trecho a seguir nos ajuda a pensar essa questão:

Há outras qualidades - como desenvolver apreço pela cultura, respeito pela diversidade e atitude de permanente aprendizado, questionamento e disponibilidade para a ação-que são valores humanos amplos sem qualquer especificidade disciplinar e que, portanto, devem estar integradas a todas as práticas educativas. (Ministério da Educação, 2000, p. 13)

$\mathrm{O}$ texto continua e novamente aparece algumas vezes a palavra "diversidade", porém sempre associada à cultura de maneira bem clara, não abrindo possibilidade para outras interpretações.

A parte referente a Linguagens, Códigos e suas tecnologias também não comenta nada sobre sexualidade, e quando trata de diversidade, novamente traz a ideia da cultura, como algo a ser pensado em diferenças históricas. Já na sua parte complementar: Linguagens, Códigos e suas tecnologias + , sexualidade é abordada, mas focando na sua parte biológica, mencionada no texto como uma preocupação dos(as) jovens e posteriormente em um lugar de destaque com a seguinte questão:

Conhecer o corpo humano não é apenas saber como funcionam os muitos aparelhos do organismo, mas também entender como funciona o próprio corpo e que consequências isso acarreta em decisões pessoais da maior importância, tais como fazer dieta, utilizar anabolizantes, praticar exercícios físicos e exercer a sexualidade. (Ministério da Educação, 2000, p. 150)

Notamos um retorno na tratativa do tema sexualidade, retornando à questão da biologia e focando principalmente na questão da gravidez indesejada. $\mathrm{O}$ trecho apresentado anteriormente está vinculada com a disciplina de Educação Física, e aborda sexualidade como decisão pessoal do conhecimento do corpo. 
A palavra "diversidade" novamente aparece como sinônimo de pluralidade, de assuntos que possuem vários modos de entendimento. Porém, na parte que inicia uma abordagem de gênero, diversidade já está mais voltada para sexualidade:

É indispensável que as regras alternativas sejam discutidas com o grupo, para facilitar a participação de todos e permitir uma reflexão sobre a diversidade . . . Estar atento às questões de gênero durante as aulas de Educação Física é uma forma de ajudar os jovens a construir relações com equidade, respeito pelas diferenças, somando e complementando o que os homens e as mulheres têm de melhor, compreendendo o outro e, com isso, aprendendo a serem pessoas mais abertas e equilibradas. (Ministério da Educação, 2000, p. 155)

Novamente a parte que faz referência a gênero está muito bem construída, do ponto de vista de estudiosas feministas de gênero, porém as temáticas sobre sexualidade e principalmente homossexualidade ainda são deficitárias. Consideramos contraditório que na fase onde a sexualidade está no ápice da sua vivência, os assuntos relacionados a ela sejam completamente invisibilizados, onde não existe nenhum espaço proposto através dos documentos federais para refletir sobre a temática.

A passagem de uma identidade infantil para uma identidade adulta torna indispensável que a temática da sexualidade seja abordada, e não somente isso, mas também trabalhada de maneira aprofundada (Furlani, 2011). A sexualidade faz parte da vida de todas as pessoas, e a fase de vida que se encontrarão as/os adolescentes no ensino médio apresenta uma importância especial para o tema, e certamente ele estará presente em grande parte dos comportamentos e assuntos em sala de aula.

Recaímos então na antiga questão: Para que serve a escola afinal? E a resposta falará de auxílio na formação de futuros cidadãos e cidadãs, na construção/transmissão de conhecimento, mas também falará de reprodução de padrões sociais, que perpetuam concepções, valores e clivagens sociais, fabricando sujeitos e legitimando relações de poder e hierarquias (Junqueira, 2009).
No ensino superior essa realidade não é soberana, visto que cada vez mais os estudos referentes ao tema das outras sexualidades, que não a heterossexual, ganham terreno e ocupam lugares nas bibliotecas. Além disso, podemos perceber também a presença de eventos sobre a temática dentro das academias, possivelmente reiterando a necessidade de se pensar e repensar a questão (Silva \& Nardi, 2011).

\section{Considerações Finais}

A escola é um ambiente que estará ou esteve presente inevitavelmente na vida de crianças, adolescentes e adultos. Por mais diferentes que sejam as culturas dos lugares, a escola existirá, com as suas diferenças, mas mantendo um objetivo em comum que é formar futuras/os cidadãs e cidadãos. Geograficamente falando, a escola mudará de nome, mudará seus horários de funcionamento, mudará suas estruturas curriculares, mas estará lá para construir e repassar conhecimentos.

É na escola que provavelmente continuaremos desenvolvendo nossas habilidades sociais, iniciadas no convívio familiar. Também poderá ser na escola que conheceremos nossas amigas e amigos mais íntimos, ou iniciaremos nossas vivências sexuais. Enfim, por longos anos a escola poderá fazer parte das nossas vidas e acompanhar nossa evolução biopsicossocial.

Logo, a escola exerce de fato um papel de grande importância na vida da sociedade. E os PCNs, de certa maneira, passaram a regulamentar o que seria importante ou não nessa parceria ao longo do ciclo vital. E conjuntamente com eles, a possibilidade de uma determinada homogeneidade nos conteúdos trabalhados ao longo de um país com tantas diferenças sociais e culturais.

Partindo do pressuposto então que as escolas estão seguindo os parâmetros conforme indicados para cada momento escolar, a análise dos mesmos gerou preocupações e nos fez refletir para a maneira como a sexualidade estava sendo percebida nos documentos. Apesar de profissionais competentes terem sido as/os responsáveis pela criação dos PCNs, entendemos que sexua- 
lidade no sentido que foge da biologia ainda é considerado "tabu" nos documentos, e consequentemente, nas escolas também.

A temática da sexualidade, que poderia ser trabalhada através da estimulação da reflexão sobre uma "norma" heterossexual existente em nossa sociedade, que elimina a existência de uma diversidade de relacionamentos, não é mencionada. Quando se trata de diversidade nos PCNs, o que aparece é a palavra como sinônima de "múltiplas facetas" e nunca relacionada à sexualidade.

Homossexualidade vai aparecer de modo rápido e vinculado com a ideia de que não devemos ter preconceitos nem discriminar o diferente. Em nenhum momento aparece a necessidade de promover momentos de reflexão para que possa ser pensado o desejo direcionado para a pessoa do mesmo sexo. Muito menos que existem diversas maneiras de se constituir uma família, e dentre elas famílias constituídas por dois pais ou duas mães.

Em um primeiro momento pode parecer apenas que os PCNs não englobam todas as necessidades das temáticas a serem trabalhadas, porém pode existir também uma decisão em não trabalhar essas questões. Essa hipótese da diversidade sexual não ser trabalhada de modo claro e objetivo está diretamente associada com as reações contrárias que a população, e aqui se inclui órgãos e instituições sociais normativas, apresentam quando há a possibilidade de uma mudança no cenário social.

Pode ser então que os PCNs, no que tange a diversidade sexual, tenham o propósito de iniciar uma abordagem à temática, de modo não diretivo, e assim ter a possibilidade de com o passar do tempo, ampliar a reflexão que propõe. Pode ser entendida como uma estratégia de ação, que ao invés de provocar um enfrentamento que poderá ser coibido por setores conservadores da sociedade, apresenta uma proposta que tengencia a temática, ainda considerada polêmica, para que possa servir como um início de possibilidade de transformação social.

Mas independente do propósito do modo de lidar com a diversidade sexual nos PCNs, é indiscutível a necessidade de que cada vez mais possamos ampliar as possibilidades de existência na sociedade, pois a historicidade traz consigo outros modos de ser e estar no mundo. E como a ciência também tem a função de fazer política, refletir sobre a diversidade sexual e a escola é colaborar para uma realidade em transformação, seja de modo mais cauteloso ou seja de modo mais diretivo.

\section{Referências}

Alario, C., Bengoechea, M., Lledó, E., \& Vargas, A. (1995). Nombra: en femenino y en masculino. Sevilla, España: Ministerio de Trabajo y Asuntos Sociales.

Almeida, A. C. C. H., \& Centa, M. de L. (2009). A família e a educação sexual dos filhos: Implicações para a enfermagem. Acta Paulista de Enfermagem, 22(1), 71-76. doi:10.1590/S010321002009000100012

Ariès, P. (1981). História Social da criança e da família (2. ed.). Rio de Janeiro, RJ: Zahar.

Baibich, T. M. (2002). Os Flintstones e o preconceito na escola. Educar (Curitiba), 19, 111-129.

Colling, A. (2004). A construção histórica do feminino e do masculino. In M. N. Strey, S. T. L. Cabeda, \& D. R. Prehn (Eds.), Gênero e cultura: Questões contemporâneas (Vol. 1, pp. 13-38). Porto Alegre, RS: Editora da Pontifícia Universidade Católica do Rio Grande do Sul.

Daniliauskas, M. (2011). Relações de gênero, diversidade sexual e políticas públicas de educação: Uma análise do Programa Brasil sem Homofobia (Dissertação de mestrado, Faculdade de Educação, Universidade de São Paulo, SP, Brasil).

Diniz, E. H., Barbosa, A. F., Junqueira, A. R. B., \& Prado, O. (2009). O governo eletrônico no Brasil: Perspectiva histórica a partir de um modelo estruturado de análise. Revista de Administração Pública, 43(1), 23-48. doi:10.1590/S003476122009000100003

Furlani, J. (2011). Educação sexual na sala de aula: Relações de gênero, orientação sexual e igualdade étnico-racial numa proposta de respeito às diferenças. Belo Horizonte, MG: Autêntica.

Gill, R. (2002). Análise de discurso. In M. W. Bauer \& G. Gaskel (Eds.), Pesquisa qualitativa com texto, imagem e som: Manual prático (pp. 244270). Petrópolis, RJ: Vozes. 
Góis, J. B. H., \& Soliva, T. B. (2011). A violência contra gays em ambiente escolar. Revista ESpaço Acadêmico, 11(123), 38-45.

Gold, M. A., Perrin, E. C., Futterman, D., \& Friedman, S. B. (1994). Children of gay or lesbian parents. Pediatric Review, 15(9), 354-358.

Golombok, S., \& Tasker, F. (1996). Do parents influence the sexual orientation of their children? Findings from a longitudinal study of lesbian families. Developmental Psychology, 32, 3-11. doi:10.1037/0012-1649.32.1.3

Junqueira, R. D. (2009). Homofobia nas escolas: Um problema de todo. In R. D. Junqueira (Ed.), Diversidade sexual na educação: Problematizações sobre a homofobia na escola (pp. 13-51). Brasília DF: Secretaria de Educação Continuada, Alfabetização e Diversidade, Ministério da Educação.

Veja as declarações dos ministros do STF sobre a decisão de união para casais homossexuais. (2011, 06 maio). Diário Catarinense. Recuperado em http://www.clicrbs.com.br/diariocatarinense/ jsp/default.jsp?uf=2\&section $=$ Geral\&newsID $=\mathrm{a} 3300558 . \mathrm{htm}$

Kyriakos, N. (2006). Do namoro à união estável. In I. M. C. C. Souza, Casamento- Uma escuta além do judiciário (pp. 119-140). Florianópolis, SC: Voxlegem.

Lacerda, M., Pereira, C., \& Camino, L. (2002). Um estudo sobre as formas de preconceito contra homossexuais na perspectiva das representações sociais. Psicologia: Reflexão e Crítica, 15(1), 165 178. doi:10.1590/S0102-79722002000100018

Mello, L., Grossi, M. P., \& Uziel, A. P. (2009). A escola e@s filh@s de lésbicas e gays: Reflexões sobre conjugalidade e parentalidade no Brasil. In R. D. Junqueira (Ed.), Diversidade sexual na educação: Problematizações sobre a homofobia na escola (pp. 159-181). Brasília, DF: Secretaria de Educação Continuada, Alfabetização e Diversidade, Ministério da Educação.

Meyer, D. E. E., Klein, C., \& Andrade, S. S. (2007). Sexualidade, prazeres e vulnerabilidade: Implicações educativas. Educação em Revista (Belo Horizonte), 46, 219-239.

Ministério da Educação. (2000) PCN + (Ensino Médio): Orientações educacionais complementares aos PCNs: Ciências da natureza, matemática e suas tecnologias. Brasília, DF: Autor.
Nicholson, L. (2000). Interpretando o gênero. Revista Estudos Feministas (Florianópolis), 8(2), 1-33.

Palma, Y. A. (2011) Mamãe e... mamãe? Apresentando as famílias homomaternais (Dissertação de mestrado em Psicologia Social, Faculdade de Psicologia, Pontifícia Universidade Católica do Rio Grande do Sul, Porto Alegre, RS, Brasil).

Piason, A., \& Strey, M. N. (2011). Um novo olhar em relação às mulheres: Em busca de visibilidade às lésbicas. In M. N. Strey, A. Piason, \& A. L. dos S. Julio (Eds.), Vida de mulher: Gênero, sexualidade e etnia (Vol. 7, pp. 103-128). Porto Alegre, RS: Editora da Pontifícia Universidade Católica do Rio Grande do Sul.

Rago, M. (2004). Feminismo e subjetividade em tempos pós-modernos. In C. L. Costa \& S. P. Schmidt (Eds.), Poéticas e políticas feministas (pp. 31-42). Florianópolis, SC: Mulheres.

Scarparo, H. (2000). Pesquisa histórica em Psicologia. In H. Scarparo (Ed.), Psicologia e pesquisa: Perspectivas metodológicas. Porto Alegre, RS: Sulinas.

Scott, J. (2002, jul./dez.). Fantasy echo: História e a construção da identidade. Labrys: Estudos Feministas, 1-2.

Secretaria de Educação Fundamental. (1998). Parâmetros Curriculares Nacionais: Terceiros e quartos ciclos: Orientação sexual. Brasília, DF: Autor.

Silva, F. R., \& Nardi, H. C. (2011). A construção social e política pela não-discriminação por orientação sexual. Physis: Revista de Saúde Coletiva, 21(1), 251-265. doi:10.1590/S010373312011000100015

Tasker, F. (2005). Lesbian mothers, gays fathers, and their children: A review. Developmental and Behavioral Pediatrics, 26(3), 224-240. doi:10.1097/00004703-200506000-00012

Uziel, A. P. (2007). Homossexualidade e adoção. Rio de Janeiro, RJ: Garamond.

Zambrano, E. (2006, jul./dez.). Parentalidades "impensáveis": Pais/mães homossexuais, travestis e transexuais. Horizontes Antropológicos, 12(26), 123-147. doi:10.1590/S010471832006000200006

Recebido: $31 / 05 / 2012$

$1^{a}$ revisão: $17 / 10 / 2014$ Aceite final: 11/02/2015 